Check for updates

Cite this: J. Mater. Chem. A, 2021, 9 , 14627

Received 23rd April 2021

Accepted 18th June 2021

DOI: $10.1039 / \mathrm{d} 1 \mathrm{ta0} 3405 \mathrm{~g}$

rsc.li/materials-a

\section{Separation enhanced methanol and dimethyl ether synthesis}

\begin{abstract}
Jasper van Kampen, (D)*ab Jurriaan Boon (D) a and Martin van Sint Annaland (D) ${ }^{\mathrm{b}}$
Separation enhanced reaction processes are promising process intensification strategies for carbon dioxide utilisation. In recent years, major improvements have been made in adsorption and membrane technology for the direct production of methanol and dimethyl ether from carbon dioxide rich feedstock and hydrogen. In situ water removal results in high single-pass conversions, thereby circumventing the disadvantages of conventional routes, such as the low carbon efficiency, energy intensive downstream separation and large recycles. In situ water removal by adsorption results in extremely high single-pass conversion and yield, especially in direct DME production. Membrane reactors allow for high single-pass conversion and yield, especially for methanol production. Here, we highlight recent advances in membrane and adsorption-enhanced synthesis of methanol and DME.
\end{abstract}

Methanol and dimethyl ether (DME), the simplest ether and the dehydrated form of methanol, are valuable platform chemicals and synthetic fuels. They are expected to play an important role in the energy transition, where fossil-based fuels and chemicals have to be replaced by products from renewable feedstock, including switching to bio-based feedstock and the chemical recycling of carbon dioxide. ${ }^{1}$ However, the conventional production processes are limited starting from $\mathrm{CO}_{2}$, and therefore considered unattractive. ${ }^{2,3}$ As for many other industrial $\mathrm{CO}_{2}$ utilisation processes a main hurdle is the production and efficient handling of steam., ${ }^{\mathbf{1 , 5} 5}$ Steam separation enhancement is shown to be a promising route for $\mathrm{CO}_{2}$ conversion. ${ }^{4}$ The concept of separation enhancement is based on Le Chatelier's principle, where an equilibrium limited reaction is shifted to enhance conversion by selectively removing reaction products, and is mainly utilised for various processes and products considering $\mathrm{CO}_{2}$ separation. ${ }^{6,7}$ The recent review and outlook by van Kampen et al. (2019) addressed the opportunities of adsorptive and membrane reactors for $\mathrm{CO}_{2}$ utilisation processes, discussing the advantages and the future developments for both technologies. Crucial aspects discussed are the hydrothermal stability of the membranes and their permselectivity, whereas high temperature working capacities and heat management are crucial aspects for reactive steam adsorption processes. ${ }^{4}$

Thermal stability of polymer membranes limits their temperature of operation, requiring more active low temperature catalysis, a topic which also gained a lot of attention in the

${ }^{a}$ Sustainable Technologies for Industrial Processes, TNO Energy Transition, P.O. Box 15, 1755 ZG Petten, The Netherlands. E-mail: jasper.vankampen@tno.nl

${ }^{b}$ Chemical Process Intensification, TU/e, P.O. Box 513, 5600 MB Eindhoven, The Netherlands. E-mail: j.v.kampen@tue.nl recent years. While zeolite membranes have been shown to outperform the other membrane types in steam permeance and selectivity at higher temperatures, their stability, mainly associated to defects, remains a point of attention. Recently Li et al. (2020) have created a defect-free zeolite $(\mathrm{NaA})$ membrane and have shown its performance in a membrane reactor for $\mathrm{CO}_{2}$ conversion to methanol. ${ }^{8}$ Indeed, Fig. 1 illustrates the important progress made in membrane reactors for methanol synthesis from 2004 (zeolite), to 2015 (polymer), to 2020 (zeolite). ${ }^{8-10}$ Gallucci et al. (2004) have shown good performance of a zeolite membrane reactor. The $\mathrm{CO}_{2}$ conversion was higher than for a traditional reactor at similar conditions, but the improvement remained modest with a yield of $8.7 \% .^{9}$ In the CARENA project (2011-2015) polymer membranes have been developed and tested for their eased production and lower costs

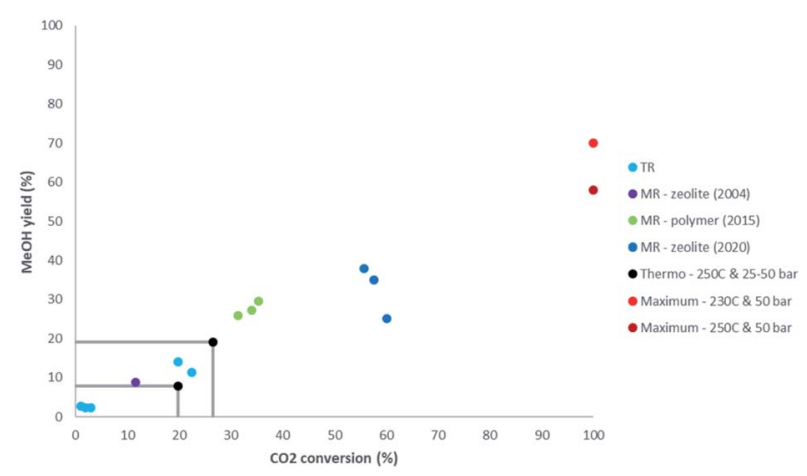

Fig. 1 Comparison of $\mathrm{CO}_{2}$ conversion and methanol yield for membrane reactors (MR) with results for traditional reactors (TR). TR: light blue. ${ }^{9,11}$ MR (2004): purple. ${ }^{9}$ MR (2015): green. ${ }^{10}$ MR (2020): dark blue. ${ }^{8}$ Thermodynamic equilibrium at $250{ }^{\circ} \mathrm{C}$ and $25-50$ bar: black. Theoretical maximum at $230-250{ }^{\circ} \mathrm{C}$ and 50 bar: red. 
compared to zeolite membranes. Although limited by lower operating temperatures and therefore reduced catalyst activity, thermodynamic equilibria for traditional methanol synthesis have been exceeded by measured yields up to $30 \%{ }^{10}$ In Fig. 1 also the maximum single-pass methanol yield is shown. A fundamental limit exists in the maximum methanol yield that can be achieved using separation enhancement, because even though the synthesis of methanol from $\mathrm{CO}$ is also equilibrium limited, it does not produce water. Therefore, even by removing all water and achieving full $\mathrm{CO}_{2}$ conversion, a mixture of methanol and $\mathrm{CO}$ will remain, of which the composition is dictated by thermodynamics. Ongoing research should lead to improving cost efficiency, focusing on the large scale production of defect-free zeolite membranes, improved selectivity and permeance of cheaper polymer membranes, and improved operation and system integration.

In the direct synthesis of DME a maximum single-pass yield of $100 \%$ could theoretically be achieved by removal of all byproduct water (Fig. 2). The developed NaA zeolite membrane reactor was also demonstrated in the direct production of DME from $\mathrm{CO}_{2}$, achieving a single-pass conversion up to $73 \%$ and a DME yield up to $54.5 \% .^{11}$ In parallel, sorption enhanced technology for the production of DME has been developed and scaled up in recent years..$^{\mathbf{4 1 2}-18}$ Interestingly, the most promising materials for high temperature steam adsorption are again LTAtype zeolites. LTA zeolites, and specifically 3A, are highly selective for water due to size exclusion by the limited pore size. ${ }^{14}$ Whereas the preferential permeation of polar molecules (water and methanol) is observed for various zeolitic membranes (FAU and MFI) and can be explained by a preferential adsorption mechanism rather than a size exclusion mechanism. ${ }^{4}$ The recent experimental validation of pressure swing regeneration in sorption enhanced DME synthesis (SEDMES), already demonstrating a factor four increase in productivity, has opened up further process optimisation by cycle design. ${ }^{13,15}$ For sorption enhanced DME synthesis from $\mathrm{CO}_{2}$, conversions up to $99 \%$ and DME yields of up to $82 \%$ have been reported. ${ }^{4}$ Adsorption technologies are very well suited for

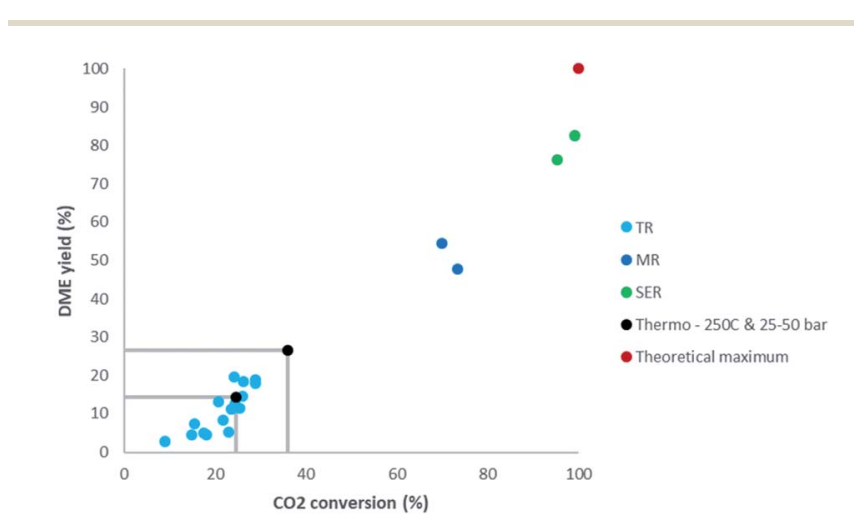

Fig. 2 Comparison of $\mathrm{CO}_{2}$ conversion and DME yield for sorption enhanced reactors (SER) and membrane reactors (MR) with results for traditional reactors (TR). TR: light blue. ${ }^{11} \mathrm{MR}$ : dark blue. ${ }^{11}$ SER: green. ${ }^{4,15}$ Thermodynamic equilibrium at $250{ }^{\circ} \mathrm{C}$ and $25-50$ bar: black. Theoretical maximum: red. steam level reductions as low as trace amounts, thereby maximising $\mathrm{CO}_{2}$ conversion. The product distribution consists of DME and some remaining, unconverted CO. As illustrated by the methanol synthesis, an equilibrium between methanol and CO remains even at dry conditions and consequently for conversion of the remaining $\mathrm{CO}$ to DME even deeper drying is required. Although the concept of sorption enhanced methanol synthesis has been demonstrated by several authors, the performances are limited, obtaining more CO than methanol, and more research is required to assses the suitability of the process. $^{19,20}$ Ongoing research, ultimately improving the cost efficiency, focuses on cycle design, i.a. faster cycling, improved operating conditions, closely linked to the system integration.

In conclusion, recent developments in separation enhanced reaction processes using membranes and adsorbents, have proven their potential for carbon dioxide conversion to methanol and DME. Both technologies outperform traditional reactor concepts, achieving single-pass conversions far beyond equilibrium. In situ water removal by adsorption allows deep drying and results in extremely high single-pass conversion and yield, especially in DME production. Membrane reactors allow for high single-pass conversion and yield, especially for methanol production. Techno-economic and life cycle analyses of the various, suitable process intensifications, such as adsorption and membranes processes, but also condensation and absorption processes for methanol synthesis, ${ }^{\mathbf{2 1 - 2 4}}$ would allow for the appropriate reactor selection for a specific case.

\section{Conflicts of interest}

There are no conflicts to declare.

\section{Acknowledgements}

Mrs M. Saric is kindly acknowledged for the fruitful discussions on membrane and adsorption-enhanced reactors.

\section{References}

1 G. Centi and S. Perathoner, Opportunities and prospects in the chemical recycling of carbon dioxide to fuels, Catal. Today, 2009, 148, 191-205.

2 V. Dieterich, A. Buttler, A. Hanel, H. Spliethoff and S. Fendt, Power-to-liquid via synthesis of methanol, DME or FischerTropsch-fuels: a review, Energy Environ. Sci., 2020, 13, 3207-3252.

3 R. J. Detz, J. N. H. Reek and B. C. C. van der Zwaan, The future of solar fuels: when could they become competitive?, Energy Environ. Sci., 2018, 11, 1653-1669.

4 J. van Kampen, J. Boon, F. van Berkel, J. Vente and M. van Sint Annaland, Steam separation enhanced reactions: review and outlook, Chem. Eng. J., 2019, 374, 1286-1303.

5 A. Katelhon, R. Meys, S. Deutz, S. Suh and A. Bardow, Climate change mitigation potential of carbon capture and utilization in the chemical industry, Proc. Natl. Acad. Sci. U. S. A., 2019, 116, 11187-11194. 
6 A. E. Rodrigues, L. M. Madeira, Y.-J. Wu and R. Faria, Sorption Enhanced Reaction Processes, World Scientific, 2017.

7 Sorption Enhancement of Chemical Processes, ed J. C. Abanades, J. Boon, P. Cobden, K. Coenen, D. S. M. Constantino, R. P. V. Faria, J. R. Fernández, F. Gallucci, M. C. Iliuta, A. E. Rodrigues, E. van Dijk, M. van Sint Annaland and A. Lemonidou, Academic Press, 1st edn, 2017, vol. 51.

8 H. Li, C. Qiu, S. Ren, Q. Dong, S. Zhang, F. Zhou, X. Liang, J. Wang, S. Li and M. Yu, $\mathrm{Na}^{+}$-gated water-conducting nanochannels for boosting $\mathrm{CO}_{2}$ conversion to liquid fuels, Science, 2020, 367, 667-671.

9 F. Gallucci, L. Paturzo and A. Basile, An experimental study of $\mathrm{CO}_{2}$ hydrogenation into methanol involving a zeolite membrane reactor, Chem. Eng. Process., 2004, 43, 1029-1036.

10 CARENA, Catalytic membrane reactor based on new materials for C1-C4 valorization, Petten, 2011.

11 H. Li, S. Ren, S. Zhang, S. Padinjarekutt, B. Sengupta, X. Liang, S. Li and M. Yu, The high-yield direct synthesis of dimethyl ether from $\mathrm{CO}_{2}$ and $\mathrm{H}_{2}$ in a dry reaction environment, J. Mater. Chem. A, 2021, 9, 2678-2682.

12 J. van Kampen, J. Boon, J. Vente and M. van Sint Annaland, Sorption enhanced dimethyl ether synthesis for high efficiency carbon conversion: modelling and cycle design, J. CO2 Util., 2020, 37, 295-308.

13 J. van Kampen, S. Booneveld, J. Boon, J. Vente and M. van Sint Annaland, Experimental validation of pressure swing regeneration for faster cycling in sorption enhanced dimethyl ether synthesis, Chem. Commun., 2020, 56, 13540-13542.

14 J. van Kampen, J. Boon and M. van Sint Annaland, Steam adsorption on molecular sieve 3A for sorption enhanced reaction processes, Adsorption, 2021, 27, 577-589.

15 J. van Kampen, J. Boon, J. Vente and M. van Sint Annaland, Sorption enhanced dimethyl ether synthesis under industrially relevant conditions: experimental validation of pressure swing regeneration, React. Chem. Eng., 2021, 6, 244-257.
16 J. Boon, J. van Kampen, R. Hoogendoorn, S. Tanase, F. P. F. van Berkel and M. van Sint Annaland, Reversible deactivation of $\gamma$-alumina by steam in the gas-phase dehydration of methanol to dimethyl ether, Catal. Commun., 2019, 119, 22-27.

17 D. Liuzzi, C. Peinado, M. A. Peña, J. van Kampen, J. Boon and S. Rojas, Increasing dimethyl ether production from biomass-derived syngas via sorption enhanced dimethyl ether synthesis, Sustainable Energy Fuels, 2020, 4, 5674-5681.

18 S. Guffanti, C. G. Visconti, J. van Kampen, J. Boon and G. Groppi, Reactor modelling and design for sorption enhanced dimethyl ether synthesis, Chem. Eng. J., 2021, 404, 126573-126585.

19 J. Terreni, M. Trottmann, T. Franken, A. Heel and A. Borgschulte, Sorption-Enhanced Methanol Synthesis, Energy Technol., 2019, 7, 1801093-1801101.

20 P. Maksimov, A. Laari, V. Ruuskanen, T. Koiranen and J. Ahola, Methanol synthesis through sorption enhanced carbon dioxide hydrogenation, Chem. Eng. J., 2021, 418, 129290-129303.

21 J. G. van Bennekom, R. H. Venderbosch, J. G. M. Winkelman, E. Wilbers, D. Assink, K. P. J. Lemmens and H. J. Heeres, Methanol synthesis beyond chemical equilibrium, Chem. Eng. Sci., 2013, 87, 204-208.

22 M. J. Bos and D. W. F. Brilman, A novel condensation reactor for efficient $\mathrm{CO}_{2}$ to methanol conversion for storage of renewable electric energy, Chem. Eng. J., 2015, 278, 527-532.

23 K. R. Westerterp, M. Kuczynski and C. H. M. Kamphuis, The synthesis of methanol in a reactor system with interstage product removal, Process Engineering and Design, 1989, 28, 763-771.

24 J. Reichert, S. Maerten, K. Meltzer, A. Tremel, M. Baldauf, P. Wasserscheid and J. Albert, Shifting the equilibrium of methanol synthesis from $\mathrm{CO}_{2}$ by in situ absorption using ionic liquid media, Sustainable Energy Fuels, 2019, 3, 33993405 . 